\title{
Correction to: Prediction accuracy improvement for Bitcoin market prices based on symmetric volatility information using artificial neural network approach
}

\author{
Anwar Hasan Abdullah Othman ${ }^{1} \cdot$ Salina Kassim ${ }^{1} \cdot$ Romzie Bin Rosman ${ }^{1} \cdot$ Nur Harena Binti Redzuan ${ }^{1}$
}

Published online: 9 March 2020

(c) Springer Nature Limited 2020

Correction to: Journal of Revenue and Pricing Management https://doi.org/10.1057/s41272-020-00229-3

The original version of this article unfortunately contained a mistake. Prediction accuracy percentage in Fig. 7, which represent the key findings of this study which is (92.147\%) does not appear in Fig. 7.

The corrected Fig. 7 with caption is given below.

\section{Prediction}

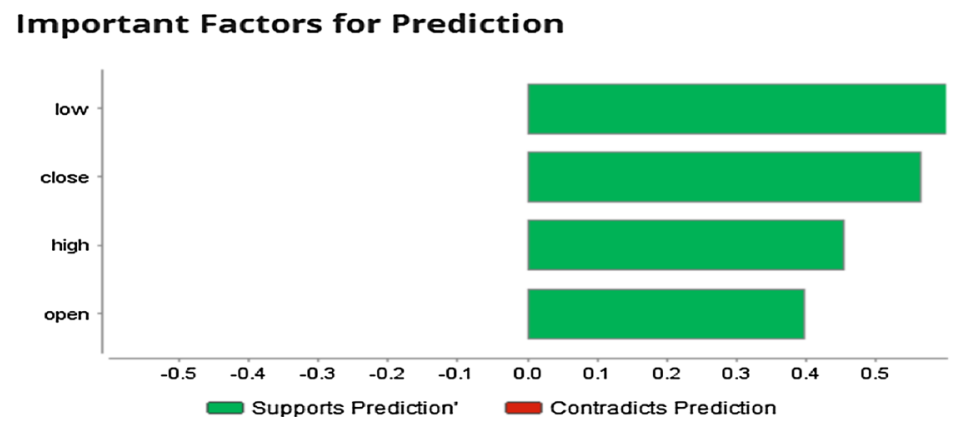

Accuracy

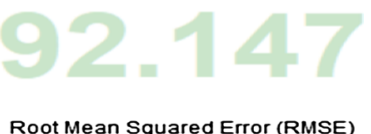

Relative Error: $3.29 \%$

Fig. 7 Distributions of prediction trend accuracy for Bitcoin Price Index

The original article can be found online at https://doi.org/10.1057/ s41272-020-00229-3.

Anwar Hasan Abdullah Othman

anwarhasan@iium.edu.my

Salina Kassim

ksalina@iium.edu.my

Romzie Bin Rosman

romzie@iium.edu.my

Nur Harena Binti Redzuan

nurharena@iium.edu.my

IIUM Institute of Islamic Banking and Finance (IIiBF), International Islamic University Malaysia, P.O. Box 10, 50728 Kuala Lumpur, Malaysia
Publisher's Note Springer Nature remains neutral with regard to jurisdictional claims in published maps and institutional affiliations. 